Article

\title{
Reliance on God's Help Scale as a Measure of Religious Trust-A Summary of Findings
}

\section{Arndt Büssing ${ }^{1, *}$, Daniela Rodrigues Recchia ${ }^{1}$ and Klaus Baumann ${ }^{2}$}

1 Quality of Life, Spirituality and Coping, Institute for Integrative Medicine, Witten/Herdecke University, Gerhard-Kienle-Weg 4, 58313 Herdecke, Germany; E-Mail: Daniela.RodriguesRecchia@uni-wh.de

2 Caritas Science and Christian Social Work, Faculty of Theology, Albert-Ludwig University, Platz der Universität 3, 79098 Freiburg, Germany; E-Mail: Klaus.Baumann@theol.uni-freiburg.de

* Author to whom correspondence should be addressed; E-Mail: arndt.buessing@uni-wh.de; Tel.: +49-2330-623-246; Fax: +49-2330-623-810.

Academic Editor: John P. Bartkowski

Received: 19 August 2015 / Accepted: 25 November 2015 / Published: 27 November 2015

\begin{abstract}
This paper gives a summary of findings from studies using the five-item Reliance on God's Help (RGH) scale, which was developed a decade ago as an integral part of a comprehensive measure to differentiate between external and internal adaptive coping strategies. It has been used for both healthy and diseased persons. We will summarize data on internal reliability scores and the distribution of mean values for the respective items in the different study samples. Also, we will present a structural equation model (SEM) to confirm the scale's validity. Our analysis shows that the RGH scale is a short, valid, and reliable measure of a person's strong basic trust in God (faith), regardless of what life brings. The items do not address aspects such as well-being, inner peace, or specific moods. Thus, it is important to note that the RGH scale was not per se associated with indicators of well-being or health-related quality of life, indicating distinct dimensions.
\end{abstract}

Keywords: Reliance on God's help; religious trust; faith; questionnaire; validation; chronic illness; healthy persons; life satisfaction; quality of life; well-being 


\section{Background}

Since its beginnings, the psychology of religion [1] has had a strong current of research focused on investigating the functions of religious beliefs as they relate to cognitions, emotions, and behaviors, e.g., regarding physical and mental health, coping with critical life events, or managing stress in general [2]. According to the Transactional Model of Stress [3], when a person is confronted with significant health problems or life stressors, after at least two rounds of appraisal to assess the relevance of the stressor, its controllability, and the availability of coping resources, he or she may use distinct strategies to deal with these stressors. With respect to the Locus of Control concept [4,5], one may turn to external sources of help or may rely on personal (internal) resources to control the situation and stressor. In the case of illness, a common external resource of help might be a medical doctor. However, not all problems can be solved, and thus persons "have to adapt and find ways to maintain physical, emotional and spiritual health-despite their symptoms" [6]. Often, people may search for further ("more powerful") external sources and look to transcendent sources of help (i.e., "God").

This strategy may be a reactive process in response to a stressor (resulting in prayers for help), a lifelong trained habit (in terms of a "trait"), or the conviction that faith is a stronghold and God is at one's side whatever life brings [6]. This can be regarded as a strong basic trust in God, who is expected to carry one through such phases of insecurity or illness. As a result, people who rely on theistic beliefs may pray for various reasons: to connect with the Sacred (communication), to become healthy again (invocation), or to articulate fears and worries without any further expectation of healing (which nevertheless may result in feelings of relief). Interestingly, research on this topic has shown that most patients with chronic diseases pray with the intention of finding relief from their suffering; they do not necessarily pray to receive healing, but to "positively transform the experience of their illness" [7].

In addition, such reliance on God's help does not necessarily mean that people passively wait for God to do the job; they also actively rely on their internal resources and consult medical doctors [8-10]. Such trust in God (referring to Proverbs 3:5) may imply the ability of a religious person to recognize God's presence in everything that happens, and therefore hold the conviction that God is at one's side, even in bad times. This may strengthen their hope, their confidence to utilize their own resources (with God's support), and their commitment to connect with God consciously through prayer.

\section{The Reliance on God's Help Scale: Description of Items}

To operationalize this trust in a transcendent (theistic) source, the Reliance on God's Help (RGH) scale (alternatively entitled Trust in God's Help scale) was developed about 10 years ago as part of a larger construct to address adaptive coping strategies related to the "locus of health control" concept $[10,11]$. The items were designed so as to be kept separate from aspects of psycho-emotional well-being, thankfulness, or feelings of spiritual peace or comfort. Conceptually, the five-item RGH scale is similar to SpREUK's [SpREUK is an acronym of the German translation of "Spiritual and Religious Attitudes in Dealing with Illness"] (religious) Trust scale and also uses one of its 
items $[12,13]$. From a theoretical point of view, the scale's topics differ from Pargament's concept of Religious Coping [14], which addresses the function of problem solving and differentiates between three styles: a deferring style (God will solve the problems), a self-directing style (use resources God has given to solve the problems on their own), and a collaborative style (problems are solved together with God) [15]. With the exception of one prayer item, the RGH scale does not refer to active coping strategies to restore health. Instead, it addresses the following topics:

Unconditional trust ("Whatever happens, I will trust in a higher power that carries me through")

Hopeful belief ("I have strong belief that God will help me")

Faith as a resource ("My faith is a stronghold, even in hard times")

Connection and effect/function ("I pray to become healthy again")

Behavioral correspondence ("I try to live in accordance with my religious convictions")

These items were scored on a five-point scale from disagreement to agreement, and the mean scores were transformed to a $100 \%$ level (transformed scale score).

\section{Reliance on God's Help Scale: Internal Reliability Data and the Structural Equation Model}

The internal reliability of the RGH scale was very good in most tested samples of healthy and diseased persons (Cronbach's alpha between 0.90 and 0.96) (Table 1). However, in a sample of Catholic pastoral workers, who all agreed with the statements, its internal reliability was acceptable yet lower (alpha $=0.78)$. Accuracy (corrected item — scale correlation) of the scale items was high in all samples (Table 1). Using the complete data sets, explorative factor analysis (Varimax rotation) of the scale (alpha $=0.96)$ determined one single factor which explained $84 \%$ of variance.

Table 1. Descriptive data with the RGH scale applied in different samples (data were calculated using the data sets of respective samples).

\begin{tabular}{|c|c|c|c|c|c|}
\hline & $\begin{array}{c}\text { Healthy } \\
\text { persons [11] * }\end{array}$ & $\begin{array}{c}\text { Chronic pain } \\
\text { diseases [9] }\end{array}$ & $\begin{array}{c}\text { Female } \\
\text { cancer }[8]\end{array}$ & $\begin{array}{c}\text { Depressive/addictive } \\
\text { diseases [16] }\end{array}$ & $\begin{array}{c}\text { Pastoral } \\
\text { workers [17] * }\end{array}$ \\
\hline Sample size (n) & 3.593 & 448 & 390 & 110 & 5.460 \\
\hline Mean age (years) & $63.9 \pm 11.3$ & $54.0 \pm 14.9$ & $59.7 \pm 7.3$ & $47.5 \pm 10.1$ & - \\
\hline Cronbach's alpha & 0.90 & 0.94 & 0.96 & 0.94 & 0.78 \\
\hline $\begin{array}{c}\text { Corrected } \\
\text { Item-Scale } \\
\text { Correlation }\end{array}$ & 0.77 to 0.87 & 0.79 to 0.92 & 0.82 to 0.93 & 0.77 to 0.91 & 0.46 to 0.66 \\
\hline $\begin{array}{c}\text { RGH Score } \\
(M \pm \mathrm{SD})\end{array}$ & $54.7 \pm 34.8$ & $55.3 \pm 33.1$ & $56.5 \pm 35.0$ & $45.8 \pm 34.0$ & $83.8 \pm 14.0$ \\
\hline $\begin{array}{l}\text { Agreement to } \\
\text { Specific } \\
\text { Statements }\end{array}$ & \multicolumn{5}{|c|}{ Scores $(\%)$ : no-undecided-yes } \\
\hline
\end{tabular}


Table 1. Cont.

\begin{tabular}{|c|c|c|c|c|c|}
\hline & $\begin{array}{c}\text { Healthy } \\
\text { persons [11] * }\end{array}$ & $\begin{array}{c}\text { Chronic pain } \\
\text { diseases [9] }\end{array}$ & $\begin{array}{c}\text { Female } \\
\text { cancer [8] }\end{array}$ & $\begin{array}{c}\text { Depressive/addictive } \\
\text { diseases [16] }\end{array}$ & $\begin{array}{c}\text { Pastoral } \\
\text { workers [17] * }\end{array}$ \\
\hline \multicolumn{6}{|l|}{ a35 "Whatever } \\
\hline happens, I will & 34 & 30 & 27 & 36 & 2 \\
\hline trust in a higher & 16 & 23 & 16 & 26 & 4 \\
\hline $\begin{array}{c}\text { power that carries } \\
\text { me through" }\end{array}$ & 50 & 47 & 57 & 39 & 94 \\
\hline a36 "I have strong & 32 & 29 & 30 & 40 & 2 \\
\hline belief that God & 18 & 23 & 17 & 21 & 8 \\
\hline will help me" & 50 & 49 & 53 & 39 & 90 \\
\hline a37 "My faith is a & 31 & 29 & 30 & 40 & 2 \\
\hline stronghold, even & 18 & 22 & 15 & 20 & 8 \\
\hline in hard times" & 51 & 49 & 55 & 40 & 90 \\
\hline a38 "I pray to & 40 & 35 & 34 & 54 & 2 \\
\hline become healthy & 16 & 16 & 13 & 12 & 6 \\
\hline again" $* *$ & 45 & 49 & 54 & 34 & 93 \\
\hline \multirow{3}{*}{$\begin{array}{l}\text { a } 39 \text { "I try to live } \\
\text { in accordance } \\
\text { with my religious } \\
\text { convictions" }\end{array}$} & 37 & 35 & 36 & 49 & 8 \\
\hline & 17 & 19 & 20 & 20 & 9 \\
\hline & 46 & 46 & 44 & 32 & 83 \\
\hline
\end{tabular}

* Subsample of the whole data set $(\mathrm{n}=5830)$; ** For healthy pastoral workers, the phrasing was changed to "I pray that I am able to cope with arising problems".

In most tested samples, a majority indicated that they have trust in a higher power, that faith is a stronghold for them, and that they believe God will help them (Table 1), i.e., about half of the enrolled persons would agree, and one-third would disagree. Nevertheless, this does not necessarily mean that all persons would pray to become healthy again (34\%-54\% would not); particularly, persons with depressive and/or addictive diseases are less likely to pray for this (Table 1).

To analyze how the RGH relates to these five items, we relied on a structural equation model (Figure 1) using the combined data sets (without pastoral workers to avoid systematic ceiling effects related to their profession). These five variables contributed significantly to explaining the $\mathrm{RGH}$ as they are components of a regression model with similar weights as the RGH. Moreover, they also have an unobserved common variance in between, which indicates communality between all five. The variables also correlated with each other. Interestingly, "strong belief that God will help" (a36) and "living in accordance with religious convictions" (a39) have a very weak negative relationship $(\mathrm{r}=-0.16)$. 


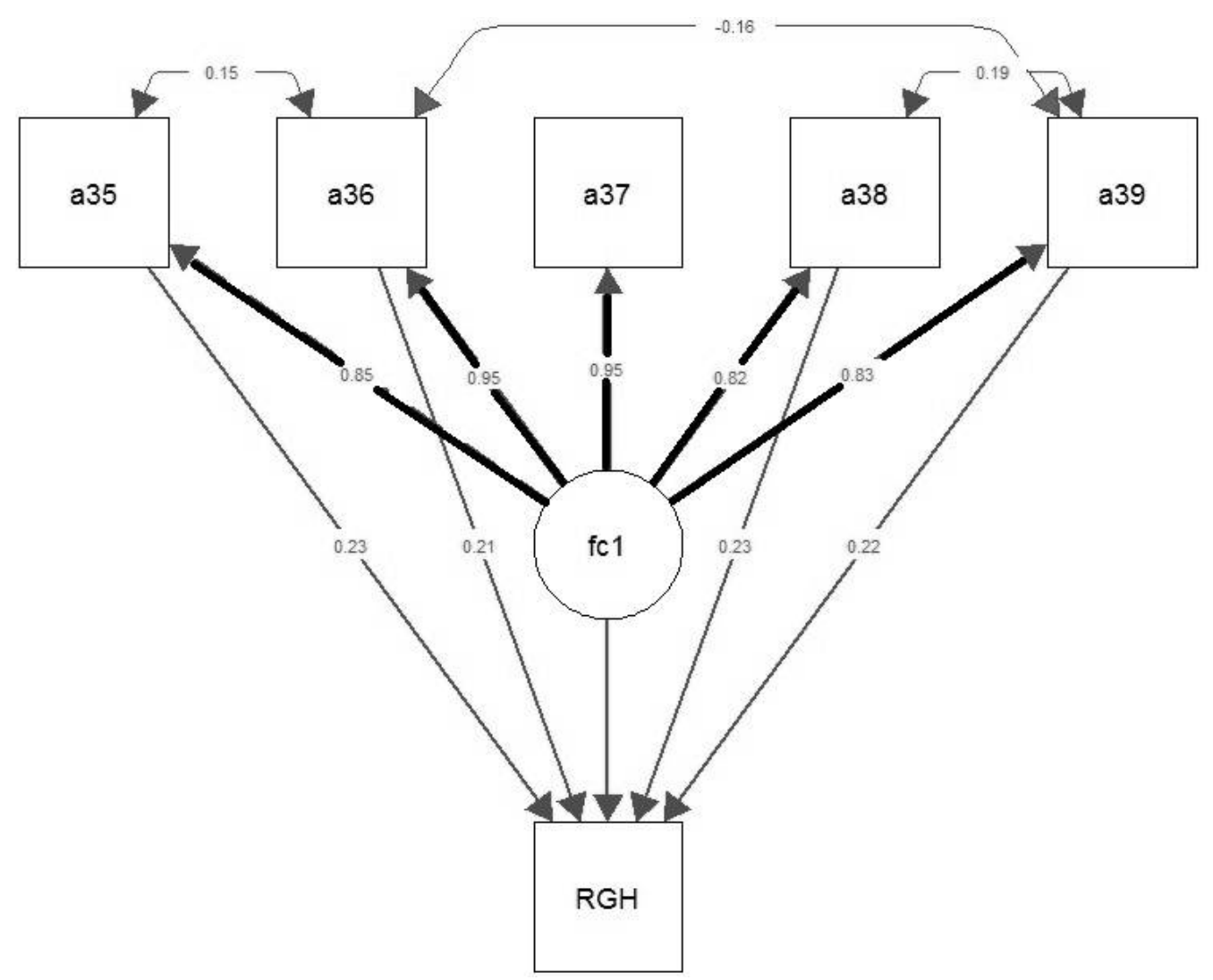

Figure 1: Structural equation model of RGH items (a35, a36, a37, a38, a39).

Small arrows between items and scale (RGH) describe regression coefficients (beta), thick arrows between items and factor (fc1) describe the standardized parameters from the factor analysis, while thin arrows between items describe correlations (r).

The structural equation model (SEM) presented below contains both the regression model for RGH and the factor analysis. The goodness of fit for this SEM model confirms its validity $(\mathrm{CFI}=1.0$, $\mathrm{TLI}=0.99$, RMSEA $=0.045, \mathrm{SRMR}=0.003$ ).

In the following sections, we describe how the mean scores of the RGH scale were distributed in different samples, the influence of sociodemographic data, which variables may be related, and findings from previous studies and analyses [8-11,16,17].

\section{Distribution of RGH Scores in Different Samples}

In a large sample of German health insurance recipients [9], we analyzed the subgroup of healthy persons (mean age $64 \pm 11$ years of age; 70\% male) derived from [11]. Here, the RGH scale had a mean score of $54.7 \pm 34.8$ (Table 1). Age had a relevant influence $(F=45.1 ; p<0.0001)$, with the lowest scores in younger persons $(<40$ years: $43.2 \pm 32.8)$ and the highest in older persons ( $>80$ years: $71.5 \pm 32.0)$. Women had higher RGH scores than men $(60.1 \pm 35.6$ versus $52.5 \pm 34.2 ; F=35.8$; $p<0.001)$; however, level of education had no relevant influence $(F=1.2$; ns.). Within the larger sample [11], the subgroup of patients with cancer had higher RGH scores $(61.4 \pm 34.0)$ than those with 
other chronic diseases $(54.0 \pm 34.4)$ or healthy individuals $(54.8 \pm 34.8)$. These differences were statistically significant $(F=6.1 ; p<0.0001)$.

In patients with chronic pain diseases (mean age $53.9 \pm 15.9$ years; $84 \%$ female; $77 \%$ Christian affiliation, $5 \%$ other, $18 \%$ none) [9], the RGH scale had a mean score of $55.3 \pm 33.1$ (Table 1). Here, women had significantly higher scores than men $(F=5.3 ; p=0.022)$.

In a sample of cancer patients (mean age $59.7 \pm 7.3$; all but one were female; $69 \%$ Christians, $31 \%$ no religious denomination) [8], the RGH score was $56.5 \pm 35.0$ (Table 1). As one would expect from the aforementioned findings, patients with a Christian affiliation scored significantly higher on the RGH scale than in those without a religious denomination $(72.2 \pm 25.2$ versus $22.6 \pm 28.0 ; F=299.5$; $p<0.0001$ ), indicating criterion validity.

In patients with depressive and/or addictive disorders (mean age $47.5 \pm 10.1 ; 51 \%$ women; $68 \%$ Christians, $1 \%$ other, $31 \%$ no religious denomination) [16], the scale's mean score was lowest $(45.8 \pm 34.0)$ (Table 1$)$. In this sample, there were no significant effects related to gender $(F=1.1$; n.s.). Still, religious denomination had an influence $(F=36.2 ; p<0.0001)$. Interestingly, patients with addictive diseases had higher scores $(59.3 \pm 37.1)$ than those with depressive $(41.2 \pm 31.9)$ or unspecified psychiatric diseases $(36.9 \pm 29.8)(F=3.6 ; p=0.030)$.

The mean RGH score in healthy and diseased samples (6550 persons) is $55.1 \pm 34$ (ranging from 0 to $100 ; 25 \%$ percentile at $25,75 \%$ percentile at 85 ).

To test the RGH scale with a positively selected sample, we used it in a study of Catholic pastoral workers, assuming that this group would have very high RGH scores [17]. From the larger sample, we analyzed a subgroup of 5460 persons (54\% were aged between $45-65$ years; $76 \%$ were male, all Christians). As expected, the scale's mean score was very high $(83.8 \pm 14.0)$. Gender had no significant influence within this sample $(F=0.4$; n.s. $)$. However, underlying profession $(F=25.2$; $p<0.0001)$ and age $(F=4.2 ; p<0.0001)$, with the highest RGH scores in very old persons $(>85$ years: $88.5 \pm 11.7)$ and the lowest in younger ones ( $<35$ years: $82.7 \pm 13.1)$, had an influence.

\section{Correlation between RGH Scores and Measures of Religiosity}

In patients with chronic diseases [9], RGH scores were strongly associated with SpREUK's religious Trust scale $(\mathrm{r}=0.77)$. Both scales are not identical (although they share one item), but have similar motifs (Table 2).

Table 2. Synoptic comparison of RGH and SpREUK's Trust scale items (with same scoring options).

\begin{tabular}{ll}
\hline RHG scale & SpREUK's Trust scale [13] \\
\hline Whatever happens, I will trust in a higher power which carries & Whatever happens, I will trust in a higher power \\
me through. & which carries me through \\
I have strong belief that God will help me. & In my mind, I am connected with a "higher source". \\
My faith is a stronghold, even in hard times. & I have faith in spiritual guidance in my life. \\
I pray to become healthy again. & I am convinced that death is not an end. \\
I try to live in accordance with my religious convictions. & In my mind, I am a religious individual. \\
\hline
\end{tabular}


Moreover, the RGH also correlated moderately with SpREUK's Search for Spiritual Support Scale $(r=0.47)$, and to a lesser extent also with the positive interpretation of illness (Reappraisal; $r=0.30$ ). With respect to the frequency of engagement in various spiritual practices, RGH correlated strongly and best with religious practices $(r=0.64)$ and gratitude/awe $(r=0.59)$ [9]. These findings indicate construct validity.

Support that the RGH is in fact a measure of religious trust and is relevant particularly for spiritual/religious persons comes from further data which shows that patients with chronic pain diseases who regard themselves as both religious and spiritual $(\mathrm{R}+\mathrm{S}+)$ had the highest $\mathrm{RGH}$ scores $(72.9 \pm 27.9)$. Those who regard themselves as religious but not as spiritual $(\mathrm{R}+\mathrm{S}-; 68.1 \pm 26.2)$ followed, and then those who see themselves as spiritual but not religious (R-S+) (41.4 \pm 32.1$)$. Patients who regarded themselves as neither religious nor spiritual $(\mathrm{R}-\mathrm{S}-$ ) had the lowest scores $(27.0 \pm 24.6)$, indicating that they do not rely on this source [9]. These results differ significantly $(F=59.5 ; p<0.0001)$ and again suggest good construct validity.

\section{Methodological Issues: RGH is not Associated with Health-Related Measures}

We believe that this compact and circumscribed scale may be beneficial in health studies. Several multidimensional instruments on spirituality, particularly when used as a one-scale measure rather than differential subscales, tend to correlate considerably with mental components of quality of life measures. Thus, to avoid "false positive" associations between RGH and measures of psychological quality of life and life satisfaction, the items of the RGH were created as to not conceptually overlap with measures of psycho-emotional well-being or feelings of spiritual peace or comfort. In our samples of persons with chronic diseases, cancer, and also healthy individuals [6], there were only marginal associations between the RGH and health-related quality of life, as measured by the Medical Outcomes Study Short-Form Health Survey SF-12 questionnaire. Also, in female cancer patients [8], the RGH was either not at all or only marginally related to cancer-related fatigue $(r=0.08)$, life satisfaction $(r=0.09)$, anxiety (0.08), depressive symptoms $(r=-0.15)$, and SF-12's mental health component $(r=-0.13)$. Similarly, in patients with depressive and/or addictive diseases [16], the RGH was weakly_but significantly_associated with life satisfaction $(r=0.24)$. However, the weak association for depression scores $(r=-0.13)$ failed to reach a level of significance.

These findings stand in contrast to results obtained with other measures of religiosity such as the Daily Spiritual Experience Scale (DSES). The DSES addresses specific experiences such as feeling God's presence, feeling God's love, a desire to be closer to God, finding strength/comfort in God, but also being touched by the beauty of creation, etc. [18,19]. One may thus assume that in religious persons the DSES is a measure of spiritual (or better, religious) well-being. In fact, in Catholic pastoral workers [17], the DSES was significantly associated with life satisfaction $(r=0.38)$, stress perception $(r=-0.29)$, and depressive symptoms $(r=-0.29)$.

Also "spiritual well-being" as measured with the Functional Assessment of Chronic Illness Therapy-Spiritual Well-being Scale (FACIT-Sp) [20,21] with its sub-constructs:

- faith (i.e., find comfort in faith; find strength in faith; difficult times have strengthened faith; know that whatever happens with illness, things will be okay), 
- meaning (i.e., have a reason for living; life has been productive; feel a sense of purpose in life; life lacks meaning and purpose), and

- peace (feel peaceful; have trouble feeling peace of mind; able to reach down deep inside myself in order to feel comfort; feel a sense of harmony)

should correlate with measures of health. These items clearly address a person's well-being, and thus one may assume inverse associations, particularly with mental health. Indeed, in female cancer survivors it is particularly the (non-religious) peace component which is moderately associated with anxiety $(r=-0.48)$ and depression $(r=-0.45)$. To a lesser extent, the (existential) component meaning correlated with anxiety $(r=-0.22)$ and depression $(r=-0.32)$, whereas the faith sub-construct was only marginally associated with depression or anxiety $(r<0.20)$ [22].

Thus, specific scales intended to measure 1) spirituality in its wider context or 2) religiosity in its more specific, faith-associated context may be associated because the constructs overlap (i.e., well-being, inner peace). On the other hand, they may not be associated because both measure different and independent dimensions. The latter seems to be true for the RGH scale and for the (religious) faith component of the FACIT-Sp.

\section{Conclusions}

Developed a decade ago as an integral part of a comprehensive measure to differentiate between external and internal adaptive coping strategies, our analysis has shown that the RGH scale is a unique measure of a person's strong basic trust in God (faith), regardless of what happens. It was used in several published studies among both healthy and diseased individuals. Our summary of findings about this short instrument indicates that the five-item RGH is a valid and reliable instrument to measure religious trust among persons with a theistic religious background. So far, there have been no longitudinal studies that have analyzed changes in the RGH during phases of existential crisis or its adjustment across illness trajectories. It is important to note, however, that this instrument is not per se associated with indicators of well-being or health-related quality of life, indicating clearly distinct dimensions. In other words, subjective religiousness consists of various dimensions, elements, and functions with different effects and meanings to the different individuals. Even empirically, religiosity cannot be reduced completely to coping or health-related functions [1].

\section{Acknowledgements}

We are grateful to all colleagues and collaborators, and to Karin Jors for her help as a native speaker.

\section{Conflicts of Interest}

The authors declare no conflict of interest. 


\section{References}

1. Klaus Baumann. "The birth of human sciences, especially psychology." In L'uomo moderno e la chiesa-atti del congresso (analecta gregoriana, 317). Edited by Paul Gilbert. Rome: Gregorian \& Biblical Press, 2012, pp. 391-408.

2. Harold G. Koenig, Dana King, and Verna Benner Carson. Handbook of Religion and Health, 2nd ed. Oxford: Oxford University Press, 2010.

3. Richard S Lazarus, and Susan Folkman. Stress, Appraisal, and Coping. New York: Springer, 1984.

4. Julian B. Rotter. "Generalized expectancies for internal versus external control of reinforcement." Psychological Monographs: General \& Applied 80 (1966): 1-28.

5. Hannah Levenson. "Multidimensional locus of control in psychiatric patients." Journal of Consulting and Clinical Psychology 41 (1973): 397-404.

6. Arndt Büssing. "Health-related quality of life and reliance on god's help." In Encyclopedia of Quality of Life and Well-Being Research. Edited by Alex C. Michalos. Dordrecht: Springer, 2014, pp. 2801-7.

7. Karin Jors, Arndt Büssing, Nield Christian Hvidt, and Klaus Baumann. "Personal prayer in patients dealing with chronic illness: A review of the research literature." Evidence-based Complementary and Alternative Medicine 2015 (2015): Article 927973.

8. Arndt Büssing, Julia Fischer, Thomas Ostermann, and Peter F. Matthiessen. "Reliance on god's help, depression and fatigue in female cancer patients." The International Journal of Psychiatry in Medicine 38 (2008): 357-72.

9. Arndt Büssing, Nadja Keller, Andreas Michalsen, Susanne Moebus, Gustav Dobos, Thomas Osterman, and Peter F. Matthiessen. "Spirituality and adaptive coping styles in german patients with chronic diseases in a cam health care setting." Journal of Complementary and Integrative Medicine 3 (2006): 1553-3840.

10. Arndt Büssing, Thomas Ostermann, and Peter F. Matthiessen. "Wer kontrolliert die Gesundheit?-Adaptive Krankheitsverarbeitungsstile bei Patienten mit chronischen Erkrankungen.” Deutsche Zeitschrift für Onkologie 40 (2008): 140-56.

11. Arndt Büssing, Thomas Ostermann, and Peter F. Matthiessen. "Adaptive coping and spirituality as a resource in cancer patients." Breast Care 2 (2007): 195-202.

12. Arndt Büssing, Thomas Ostermann, and Peter F. Matthiessen. "Role of religion and spirituality in medical patients: Confirmatory results with the SpREUK questionnaire." Health and Quality of Life Outcomes 3 (2005): 10. doi:10.1186/1477-7525-3-10.

13. Arndt Büssing. "Spirituality as a resource to rely on in chronic illness: The SpREUK questionnaire.” Religions 1 (2010): 9-17.

14. Kenneth I. Pargament. The Psychology of Religion and Coping: Theory, Research, Practice. New York: Guilford Press, 1997.

15. Russel E. Phillips III, Quinten K. Lynn, Craig D. Crossley, and Kenneth I. Pargament. "Self-directing religious coping: A deistic god, abandoning god, or no god at all?" Journal For The Scientific Study Of Religion 43 (2004): 409-18. 
16. Arndt Büssing, and Götz Mundle. "Reliance on god's help in patients with depressive and addictive disorders is not associated with their depressive symptoms." Religions 3 (2012): 455-66.

17. Eckhard Frick, Arndt Büssing, Klaus Baumann, Wolfgang Weig, and Christoph Jacobs. "Do self-efficacy expectation and spirituality provide a buffer against stress-associated impairment of health? A comprehensive analysis of the german pastoral ministry study." Journal of Religion and Health. Published electronically 27 March 2015. doi:10.1007/s10943-015-0040-7. Available online: http://link.springer.com/article/10.1007/s10943-015-0040-7.

18. Lynn G. Underwood, and Jeanne A. Teresi. "The daily spiritual experience scale: Development, theoretical description, reliability, exploratory factor analysis, and preliminary construct validity using health-related data." Annals of Behavioral Medicine: A Publication of the Society of Behavioral Medicine 24 (2002): 22-33.

19. Lynn Underwood. "The daily spiritual experience scale: Overview and results." Religions 2 (2011): 29-50.

20. Amy H. Peterman, George Fitchett, Marianne J. Brady, Lesbia Hernandez, and David Cella. "Measuring spiritual well-being in people with cancer: The functional assessment of chronic illness therapy-Spiritual well-being scale (FACIT-Sp)." Annals of Behavioral Medicine 24 (2002): 49-58.

21. Jason M. Bredle, John M. Salsman, Scott M. Debb, Benjamin J. Arnold, and David Cella. "Spiritual well-being as a component of health-related quality of life: The functional assessment of chronic illness therapy—Spiritual well-being scale (FACIT-Sp).” Religions 2 (2011): 77-94.

22. Andrea L. Canada, Patricia E. Murphy, George Fitchett, Amy H. Peterman, and Leslie R. Schover. “A 3-factor model for the FACITt-Sp." Psycho-oncology 17 (2008): 908-16.

(C) 2015 by the authors; licensee MDPI, Basel, Switzerland. This article is an open access article distributed under the terms and conditions of the Creative Commons Attribution license (http://creativecommons.org/licenses/by/4.0/). 